\title{
Factors influencing arterial stiffness in pheochromocytoma and effect of adrenalectomy
}

\author{
Ondřej Petrák ${ }^{1}$, Branislav Štrauch ${ }^{1}$, Tomáš Zelinka ${ }^{1}$, Jan Rosa ${ }^{1}$, Robert Holaj $^{1}$, Alice Vránková ${ }^{1}$, \\ Mojmír Kasalický ${ }^{2}$, Jan Kvasnička ${ }^{3}$, Karel Pacák ${ }^{4}$ and Jiří Widimský Jr ${ }^{1}$
}

The aim of the study was to evaluate arterial stiffness and its modulating factors measured by carotid-femoral pulse wave velocity (PWV) and central augmentation index (AI) in patients with pheochromocytoma (PHEO) before and after surgery. Forty-five patients with PHEO and $\mathbf{4 5}$ healthy controls were investigated using an applanation tonometer (SphygmoCor, AtCor Medical). The gender, age, BMI and lipid profiles were comparable among both groups. The main difference in basic characteristic was as expected for fasting plasma glucose $(P<0.001)$ and all blood pressure modalities. PWV in PHEO was significantly higher than in controls (7.2 \pm 1.4 vs. $\left.5.8 \pm 0.5 \mathrm{~ms}^{-1} ; P<0.001\right)$. Between-group difference in PWV remained significant even after the adjustment for age, heart rate, fasting plasma glucose and each of brachial $(P<0.001)$ and $24 \mathrm{~h}$ blood pressure parameters $(P<0.01)$. The difference in Al between groups did not reach the statistical significance $(19 \pm 14 \mathrm{vs}$. $16 \pm 13 \%$; NS). In multiple regression analysis, age $(P<0.001)$, mean blood pressure $(P=0.002)$, high-sensitive $C$-reactive protein (hs-CRP) $(P=0.007)$ and $24 \mathrm{~h}$ urine norepinephrine $(P=0.007)$ were independently associated with $P W V$ in PHEO. In addition, 27 patients with PHEO were studied 1 year after tumor removal. Successful tumor removal led to a significant decrease in PWV (7.0 \pm 1.2 vs. $\left.6.0 \pm 1.1 \mathrm{~ms}^{-1} ; P<0.001\right)$. In conclusion, patients with PHEO have an increase in PWV, which is reversed by the successful tumor removal. Age, mean blood pressure, hs-CRP and norepinephrine levels are independent predictors of PWV.

Hypertension Research (2010) 33, 454-459; doi:10.1038/hr.2010.12; published online 26 February 2010

Keywords: arterial stiffness; catecholamines; pheochromocytoma; pulse wave velocity

\section{INTRODUCTION}

Accumulating evidence suggests that catecholamines can influence vascular smooth muscle cell growth and remodeling of vascular structure, independently of hemodynamics. ${ }^{1-3}$ The accelerated deposition of extracellular matrix proteins within the blood vessel wall contributes to a progressive loss of vascular compliance, abnormalities of pulse wave morphology, augmentation of pulse pressure and increased cardiovascular stress, culminating in premature cardiovascular morbidity and mortality. ${ }^{4-7}$

Carotid-femoral pulse wave velocity (PWV) is an index of arterial stiffness and has been shown to be an independent predictor of cardiovascular mortality in hypertensive patients ${ }^{5,6,8,9}$ and a marker of cardiovascular risk in the general population. ${ }^{7,10,11}$ Arterial stiffness has not only been affected mainly by age and blood pressure, ${ }^{12}$ but also by diabetes mellitus, ${ }^{13}$ chronic renal failure ${ }^{14}$ and chronic subclinical inflammation. ${ }^{15}$

Only few data are available in human beings about the effect of chronic catecholamine overproduction on the vasculature. Pheochromocytoma (PHEO)/paraganglioma are catecholamine producing tumors arising either from adrenal medulla or sympathetic nervous system-associated chromaffin cells. Catecholamines produced by the tumor are responsible for the large variety of symptoms and signs because of their effect on hemodynamics and metabolism. ${ }^{16-18}$ Earlier study performed on s.c. small resistance arteries in normotensive patients and subjects with essential hypertension and PHEO showed that a pronounced activation of adrenergic system is not associated with s.c. vascular smooth muscle cell hypertrophy or hyperplasia. ${ }^{1}$ Furthermore, last studies found a strong carotid vascular remodeling in $\mathrm{PHEO}^{19,20}$ and the reduction in carotid IMT and wall fibrosis after surgery in these patients. ${ }^{21}$ This effect is probably directly exerted independently of the hemodynamic discharge not only on vascular wall, but also on other districts, that is cardiac tissue. ${ }^{22}$

Our study was aimed at evaluating the effect of PHEO on central arterial (aortic) stiffness measured by PWV and augmentation index (AI) in patients with $\mathrm{PHEO} /$ paraganglioma before and after tumor removal. We also focused our study to investigate factors influencing stiffness of large arteries, such as glucose levels, blood pressure variability and highsensitive C-reactive protein (hs-CRP) in patients with PHEO.

\footnotetext{
${ }^{1}$ 3rd Department of Medicine, General Faculty Hospital, 1st Medical Faculty, Charles University in Prague, Prague 2, Czech Republic; ${ }^{2}$ Department of Surgery, Central Military Hospital, 1st Medical Faculty, Charles University in Prague, Prague 2, Czech Republic; ${ }^{3}$ Central Hematology Laboratory, General Faculty Hospital, 1 st Medical Faculty, Charles University in Prague, Prague 2, Czech Republic and ${ }^{4}$ Reproductive Biology and Medicine Branch, NICHD, National Institutes of Health, Bethesda, MD, USA Correspondence: Dr 0 Petrák, 3rd Department of Medicine, General Faculty Hospital, 1st Medical Faculty, U nemocnice 1, Prague 2, 128 08, Czech Republic. E-mail: Ondrej.Petrak@vfn.cz

Received 21 September 2009; revised 7 January 2010; accepted 12 January 2010; published online 26 February 2010
} 


\section{METHODS}

Subjects

Study was designed as prospective and the patients were enrolled consecutively. We have studied 45 patients with PHEO $(22$ males $)$ in the period from October 2003 to May 2009. The diagnosis of PHEO was based on elevated 24-h urine catecholamines/equally elevated norepinephrine and epinephrine $(n=18)$, predominantly elevated norepinephrine $(n=19)$ and predominantly elevated epinephrine $(n=8) /$ and the demonstration of tumor by CT or MRI. All patients underwent surgical removal of the tumor and the diagnosis was confirmed histopathologically. Seventeen patients had diabetes mellitus, which was defined by either the medication with insulin/oral antidiabetic drugs or by repeated fasting plasma glucose $>7.1 \mathrm{mmoll}^{-1}$. $^{23}$

Patients discontinued antihypertensive medication (except non-dihydropyridine calcium channel blockers and $\alpha 1$-adrenoceptor blockers) at least 2 weeks before the examination. In fact, 38 patients were treated (31 by Doxazosin, 5 by Verapamil and 2 by combination of Doxazosin and Verapamil) for 2 weeks before the investigation.

All patients were reexamined at least 1 year after the tumor removal and 16 subjects with persistent/essential/hypertension and two subjects with malignant form were excluded from our study. Only 27 patients ( 11 with equally elevated epinephrine and norepinephrine, 6 with predominantly elevated epinephrine, and 10 with predominantly elevated norepinephrine) were found free of disease recurrence including persistent arterial hypertension and were without concomitant antihypertensive medication.

Control group included 45 normotensive healthy volunteers (C) (25 males).

Informed consent was obtained from all subjects and the study was prepared in accordance with the Helsinki Declaration and approved by the local Ethics Committee.

\section{Pulse wave analysis}

All subjects were studied after an overnight fasting in a quiet room. Subjects were always reexamined by the same investigator. After $15 \mathrm{~min}$ of rest in the supine position, the PWV and AI were measured using the applanation tonometer SphygmoCor (AtCor Medical, West Ryde, Australia). The pulse wave was acquired at the radial artery. Aortic pulse wave was derived by means of generalized transfer function and calibrated using a single simultaneous measurement of brachial artery blood pressure using an oscillometric sphygmomanometer (Dinamap, Tampa, FL, USA). The aortic (or central) AI was calculated as the ratio of the pressure difference $(\Delta P)$ between the shoulder of the wave and the peak systolic pressure according to the formula of $\mathrm{AI}=\Delta P /($ systolic $\mathrm{BP}$-diastolic $\mathrm{BP}){ }^{24}$ The $\mathrm{AI}$ values were corrected for differences in heart rate from 75 beats per min using a SphygmoCor built-in algorithm. ${ }^{24} \mathrm{~A}$ high level of repeatability and reproducibility of SphygmoCor pulse wave measurements has been established for various patient groups. ${ }^{25}$

Aortic PWV was assessed by the time difference between pulse wave upstrokes, which were consecutively recorded at the right carotid artery and right femoral artery and aligned by ECG-based trigger. The 'percentage pulse height algorithm' was used to locate the 'foot' of the pulse waves.

\section{Biochemistry and catecholamine analysis}

Blood samples for routine biochemical screening by an automatic analyzer (Modular, Roche Diagnostic, Basel, Switzerland) were taken in the morning after overnight fasting.

Urine catecholamines were analyzed by high performance liquid chromatography with fluorometric detector (HPLC/FLD 1100S, Agilent Technologies, Santa Clara, CA, USA). The system was calibrated with a catecholamine standard using the ClinRep test kit (Recipe Chemicals and Instruments GmbH, Munich, Germany).

The hs-CRP was measured only in patients with PHEO and was analyzed by means of an automatic nephelometer BN II (Dade Behring, Leiderbach, Germany): normal values, $0.0-2.9 \mathrm{mgl}^{-1}$; low detection limit, $0.175 \mathrm{mgl}^{-1}$; intraassay coefficient of variation, $2.3-4.4 \%$ and interassay coefficient of variation, $2.5-5.7 \%$.

\section{Blood pressure measurement}

Office artery blood pressure was measured according to ESH Guidelines by oscillometric sphygmomanometer (Dinamap); 24-h ambulatory blood pressure monitoring was performed using an oscillometric device Spacelabs 90207 (SpaceLabs Medical, Richmond, WA, USA), which was set to measure blood pressure every $20 \mathrm{~min}$ during the day (from 600 to 2200 hours) and every 30 min during the night (from 2200 to 600 hours). Daytime BP variability was assessed using the s.d. during the daytime period of BP in PHEO.

\section{Statistical analysis}

Statistical analysis was performed by Statistica for Windows ver.8.0 statistical software (StatSoft, Inc., Tulsa, OK, USA). Data were described as means \pm s.d. or medians (interquartile range) for non-normally distributed variables (Shapiro-Wilks $\mathrm{W}$ test). Comparison between the groups was made using Student's $t$-test or the Mann-Whitney test (for data with non-normal distribution). Analysis of paired values (data before and after operation) was performed by means of paired $t$-test or the Wilcoxon rank-sum test (for data with non-normal distribution). Pearson's correlation analysis was performed to characterize the relationship between individual variables. Non-normally distributed variables (fasting plasma glucose, catecholamine levels, hs-CRP) were $\log$-transformed $\left(\log _{10}\right)$ before this analysis. Analysis of covariance was used to adjust for the differences in clinical and biochemical characteristics. The multivariate stepwise regression model was used to identify independent determinants of PWV. $P<0.05$ was considered significant.

\section{RESULTS}

Baseline subject characteristics are summarized in Table 1. Gender ratio, body mass index, age, lipid profile and renal function did not differ significantly between the groups. Patients with PHEO had significantly higher urine catecholamines in comparison with $\mathrm{C}$ (epinephrine and norepinephrine: $P<0.001$ ), and as expected, significantly higher fasting plasma glucose $(P<0.001)$.

The differences in hemodynamic parameters and pulse wave indices are summarized in Table 2. Patients with PHEO had significantly

Table 1 Baseline characteristics of patients with pheochromocytoma and healthy controls

\begin{tabular}{|c|c|c|c|}
\hline & PHEO & C & $P$ \\
\hline Sex (female/male) & $45(23 / 22)$ & $45(20 / 25)$ & NS \\
\hline Age (years) & $47 \pm 12$ & $44 \pm 10$ & 0.167 \\
\hline BMI $\left(\mathrm{kg} \mathrm{m}^{-2}\right)$ & $25 \pm 5$ & $25 \pm 4$ & 0.929 \\
\hline Hypertension $(n)$ & $31(69 \%)$ & - & - \\
\hline Duration of hypertension (years) & $4 \pm 6$ & - & - \\
\hline Paroxysmal symptoms $(n)$ & $18(40 \%)$ & - & - \\
\hline Asymptomatic subjects $(n)$ & $3(7 \%)$ & - & - \\
\hline Treated $(n)$ & $38(84 \%)$ & - & - \\
\hline Smoking status $(n)$ & $15(33 \%)$ & $11(24 \%)$ & 0.393 \\
\hline Diabetes mellitus $(n)$ & $17(38 \%)$ & - & - \\
\hline Duration of diabetes (years) & $1 \pm 2$ & - & - \\
\hline Serum creatinine $\left(\mu \mathrm{moll} \mathrm{I}^{-1}\right)$ & $74 \pm 16$ & $77 \pm 14$ & 0.393 \\
\hline Fasting plasma glucose $\left(\mathrm{mmol}^{-1}\right)$ & $6.1 \pm 1.6$ & $4.8 \pm 0.5$ & $<0.001$ \\
\hline Total cholesterol $\left(\mathrm{mmol} \mathrm{I}^{-1}\right)$ & $5.3 \pm 1.4$ & $5.2 \pm 1.0$ & 0.682 \\
\hline HDL cholesterol $\left(\mathrm{mmol}^{-1}\right)$ & $1.5 \pm 0.4$ & $1.5 \pm 0.4$ & 0.903 \\
\hline LDL cholesterol $\left(\mathrm{mmoll}^{-1}\right)$ & $3.2 \pm 1.1$ & $3.2 \pm 0.8$ & 0.902 \\
\hline Triglycerides $\left(\mathrm{mmol} \mathrm{I}^{-1}\right)$ & $1.5 \pm 1.1$ & $1.4 \pm 0.9$ & 0.487 \\
\hline hs-CRP ( $\left.\mathrm{mg} \mathrm{l}^{-1}\right)$ & $0.89(0.32 ; 1.4)$ & NA & - \\
\hline $24 \mathrm{~h}$ urine epinephrine $\mathrm{a}^{\mathrm{a}}$ & $143(28 ; 1374)$ & $25(13 ; 35)$ & $<0.001$ \\
\hline $24 \mathrm{~h}$ urine norepinephrine $\mathrm{a}^{\mathrm{a}}$ & $1284(493 ; 3724)$ & $120(94 ; 162)$ & $<0.001$ \\
\hline
\end{tabular}

Abbreviations: BMI, body mass index; HDL, high-density lipoprotein; hs-CRP, high-sensitive C-reactive protein; LDL, low-density lipoprotein.

Values are shown as means \pm s.d. (normal distribution) or medians (interquartile range). ${ }^{a}$ nmolg ${ }^{-1}$ of creatinine. 
Table 2 Central and peripheral hemodynamic parameters in pheochromocytoma and healthy controls

\begin{tabular}{lccc}
\hline & PHEO & C & $P$ \\
\hline Heart rate (b.p.m.) & $71 \pm 14$ & $66 \pm 10$ & 0.037 \\
Brachial BP (mm Hg) & $132 \pm 22 / 76 \pm 12$ & $117 \pm 11 / 70 \pm 8$ & $<0.001 / 0.016$ \\
Mean BP (mm Hg) & $95 \pm 15$ & $86 \pm 8$ & $<0.001$ \\
Central BP (mm Hg) & $117 \pm 18 / 77 \pm 13$ & $104 \pm 10 / 71 \pm 8$ & $<0.001 / 0.013$ \\
Mean 24 h BP (mm Hg) & $127 \pm 17 / 77 \pm 11$ & $116 \pm 9 / 73 \pm 7$ & $0.005 / 0.07$ \\
Day 24 h BP (mm Hg) & $129 \pm 16 / 80 \pm 11$ & $120 \pm 9 / 77 \pm 7$ & $0.009 / 0.16$ \\
Night 24 BP (mm Hg) & $122 \pm 21 / 72 \pm 13$ & $106 \pm 11 / 66 \pm 7$ & $<0.001 / 0.02$ \\
Mean 24 h HR (b.p.m.) & $75 \pm 12$ & $70 \pm 8$ & 0.025 \\
Daytime BP variability (mm Hg) & $12 \pm 5 / 9 \pm 3$ & $10 \pm 3 / 9 \pm 2$ & $0.022 / 0.694$ \\
Augmentation index 75a & $19 \pm 14$ & $16 \pm 13$ & 0.316 \\
PWV (m s ${ }^{-1}$ ) & $7.2 \pm 1.4$ & $5.8 \pm 0.5$ & $<0.001$ \\
PWVadj (m s $\left.{ }^{-1}\right)^{\text {b }}$ & $6.9 \pm 0.1$ & $6.1 \pm 0.1$ & $<0.001$ \\
\hline
\end{tabular}

Abbreviations: $\mathrm{BP}$, blood pressure; PWV, pulse wave velocity.

Values are shown as means \pm s.d.

augmentation index for heart rate 75 beats per min.

bAdjusted for age, heart rate, brachial mean blood pressure and fasting plasma glucose.

higher all BP modalities except the mean $24 \mathrm{~h}$ and day diastolic BP. Systolic daytime blood pressure variability was significantly higher in comparison with $\mathrm{C}(P<0.05)$. Significant difference between both groups was also in office and $24 \mathrm{~h}$ heart rate $(P<0.05)$.

The PWV in patients with PHEO was significantly higher than in $\mathrm{C}(P<0.001)$. The differences in PWV remained significant even after the adjustment for age, heart rate, mean $\mathrm{BP}$ and fasting plasma glucose (Table 2). The same model was used for each of the other brachial and $24 \mathrm{~h}$ blood pressure parameters and the differences in PWV still remained significant $(P<0.001$ for brachial SBP, DBP, $P P$; $P=0.002$ for $24 \mathrm{~h} \mathrm{SBP}$ and $24 \mathrm{~h} \mathrm{DBP}$ ). Between-group difference in AI did not reach the statistical significance $(P=0.32)$ (Table 2$)$.

In the PHEO group, PWV values were positively related to age, $\mathrm{BMI}$, all blood pressure modalities, AI, heart rate, fasting plasma glucose, hs-CRP, daytime systolic BP variability and urine norepinephrine levels (Table 3 and Figure 1). Stepwise multiple regression analysis showed that age $(\beta=0.428 ; P<0.001)$, mean blood pressure ( $\beta=0.426 ; P=0.002)$, hs-CRP $(\beta=0.326 ; P=0.007)$ and urine norepinephrine $(\beta=0.443 ; P=0.007)$ were the only variables independently associated with PWV $\left(R^{2}=0.63 ; P<0.0001\right)$ in patients with PHEO.

Urine norepinephrine was also positively associated with brachial and central BP, mean $24 \mathrm{~h}$ BP, daytime systolic BP variability and PWV (Table 3; Figure 1). No similar correlation between urine catecholamine levels and PWV were found in the control group ( $\log _{10}$ epinephrine $R=-0.07, P=0.75$; $\log _{10}$ norepinephrine $R=0.20$, $P=0.37$ ).

As indicated in Table 4 surgical treatment in patients with PHEO led to normalization of catecholamine levels, blood pressure parameters, hs-CRP and plasma glucose. Change in PWV (mean difference $\left.1.1 \pm 0.9 \mathrm{~ms}^{-1} ; P<0.001\right)$ after tumor removal is illustrated in Figure 2.

\section{DISCUSSION}

This study showed that patients with PHEO have increased aortic stiffness as evidenced by an increased PWV in comparison with healthy controls. Age, mean blood pressure, hs-CRP and urine norepinephrine were independent predictors of $\mathrm{PWV}$ in patients with PHEO. The study also showed that all abnormalities, including aortic stiffness, are entirely reversed after successful tumor removal.

Blood pressure and age are main determinants of arterial stiffness. ${ }^{12}$ PHEO group presented with significantly higher blood pressure in
Table 3 Univariate correlation analysis between PWV, $\log _{10} 24 \mathrm{~h}$ urine norepinephrine and clinical/biochemical variables in subjects with pheochromocytoma

\begin{tabular}{|c|c|c|c|c|}
\hline & \multicolumn{2}{|c|}{$P W V$} & \multicolumn{2}{|c|}{$\log _{10}$ norepinephrine } \\
\hline & $\mathrm{R}$ & $\mathrm{P}$ & $\mathrm{R}$ & $\mathrm{P}$ \\
\hline Age & 0.30 & 0.048 & -0.21 & 0.177 \\
\hline BMI & 0.33 & 0.028 & -0.12 & 0.427 \\
\hline Heart rate & 0.48 & $<0.001$ & 0.23 & 0.127 \\
\hline Brachial SBP & 0.60 & $<0.001$ & 0.46 & 0.002 \\
\hline Brachial DBP & 0.52 & $<0.001$ & 0.40 & 0.006 \\
\hline Mean BP & 0.59 & $<0.001$ & 0.47 & 0.001 \\
\hline Central SBP & 0.57 & $<0.001$ & 0.44 & 0.003 \\
\hline Central DBP & 0.53 & $<0.001$ & 0.41 & 0.005 \\
\hline Al 75 & 0.29 & 0.059 & 0.06 & 0.698 \\
\hline Mean $24 \mathrm{~h}$ SBP & 0.43 & 0.003 & 0.51 & $<0.001$ \\
\hline Mean $24 \mathrm{~h}$ DBP & 0.32 & 0.030 & 0.41 & 0.005 \\
\hline Daytime SBP variability & 0.31 & 0.040 & 0.55 & $<0.001$ \\
\hline Daytime DBP variability & 0.10 & 0.528 & 0.41 & 0.006 \\
\hline $\log _{10}$ fasting plasma glucose & 0.32 & 0.031 & 0.29 & 0.050 \\
\hline $\log _{10}$ hs-CRP & 0.38 & 0.017 & -0.06 & 0.712 \\
\hline Total cholesterol & 0.11 & 0.469 & 0.25 & 0.096 \\
\hline Triglycerides & 0.07 & 0.669 & 0.09 & 0.522 \\
\hline $\log _{10} 24 \mathrm{~h}$ urine Epinephrine & -0.22 & 0.167 & -0.19 & 0.140 \\
\hline $\log _{10} 24$ h urine Norepinephrine & 0.42 & 0.004 & - & - \\
\hline
\end{tabular}

Abbreviations: Al, augmentation index; BMI, body mass index; DBP, diastolic blood pressure; hs-CRP, high-sensitive $C$-reactive protein; MBP, mean blood pressure; $\mathrm{P}$, level of significance; PWV, pulse wave velocity; $R$, the Pearson's correlation coefficient; SBP, systolic blood pressure.

comparison with control group, which might be an explanation for higher PWV in PHEO patients. The difference in PWV, however, remained significant even after the adjustment for blood pressure data.

There are other multiple direct and indirect mechanisms that may explain the increase of aortic stiffness in patients with PHEO.

Earlier in vitro studies have found that norepinephrine leads to hypertrophy and proliferation of cultured smooth muscle cells ${ }^{3}$ and also induces proliferation of adventitial fibroblasts. ${ }^{26}$ Norepinephrineinduced hypertrophy of vascular smooth muscle cells is mediated by $\alpha$-adrenoceptors. ${ }^{26} \alpha 1$-adrenoceptors of the smooth muscle cells stimulate production of collagen and fibronectin expression. ${ }^{3}$ In vivo studies using surgical or sympathetic denervation, ${ }^{27}$ systemic infusion of catecholamines ${ }^{28}$ or $\alpha$-adrenoceptor antagonists ${ }^{29}$ suggested that norepinephrine may have a direct trophic effect on the normal and injured vascular wall. ${ }^{30}$ Furthermore, positive correlation of plasma catecholamines with wall hypertrophy ${ }^{31}$ and the severity of atherosclerosis $^{32}$ were found in human beings.

We found that urine norepinephrine (but not epinephrine) excretion was positively related to PWV and BP levels. This suggests that norepinephrine may be an important determinant contributing to increased arterial stiffness in patients with PHEO. Central sympathetic outflow probably does not contribute to the alteration of arterial stiffness in PHEO, as in an earlier study surgical removal of the tumor resulted in an increase of central sympathetic drive. ${ }^{33}$

Other mechanism, which may also have a function in elevation of arterial stiffness, is higher fasting plasma glucose in patients with PHEO. ${ }^{34}$ Indeed, we observed positive correlation between PWV and fasting plasma glucose in our study. There is evidence that hyperglycemia in patients with diabetes mellitus may contribute to the proliferation of arterial smooth muscle cells and arterial stiffness, ${ }^{13,35}$ in particular by the accumulation of advanced glycation end products 


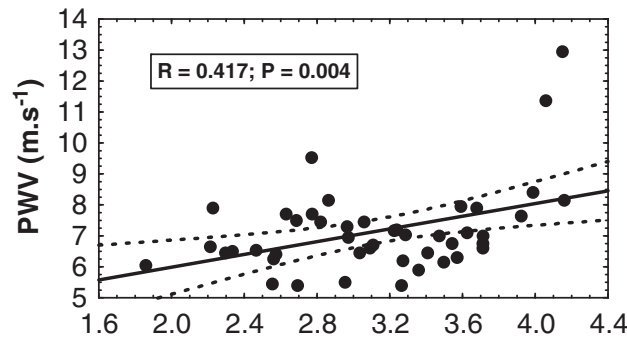

$\log _{10}$ transformed urine Norepinephrine

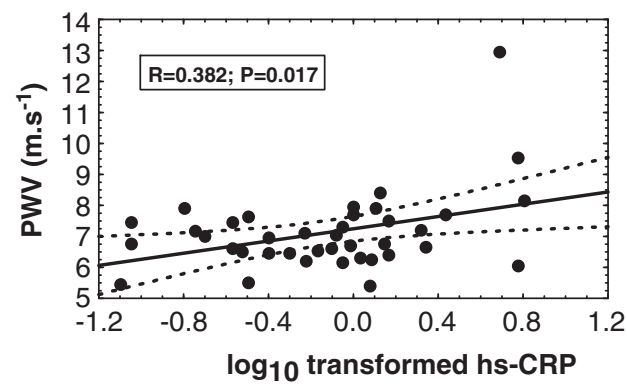

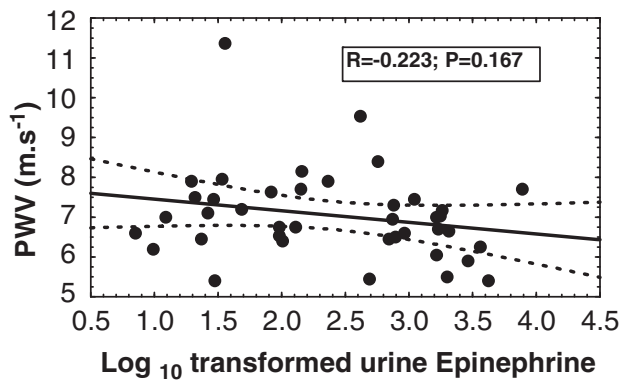

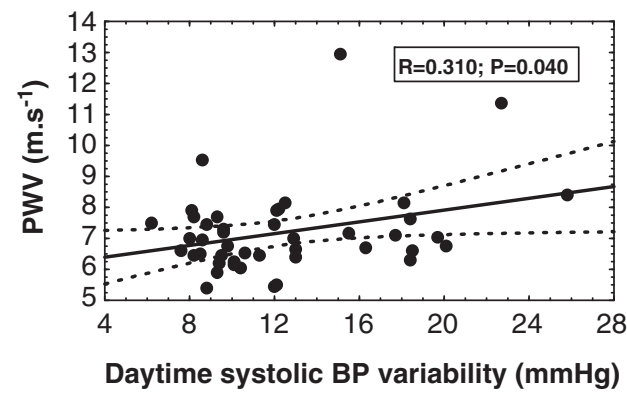

Figure 1 Univariate correlation analysis between PWV and urine norepinephrine (upper left), urine epinephrine (upper right), hs-CRP (lower left) and daytime BP variability (lower right).

Table 4 The effect of tumor removal in the subset of patients with pheochromocytoma compared with control subjects

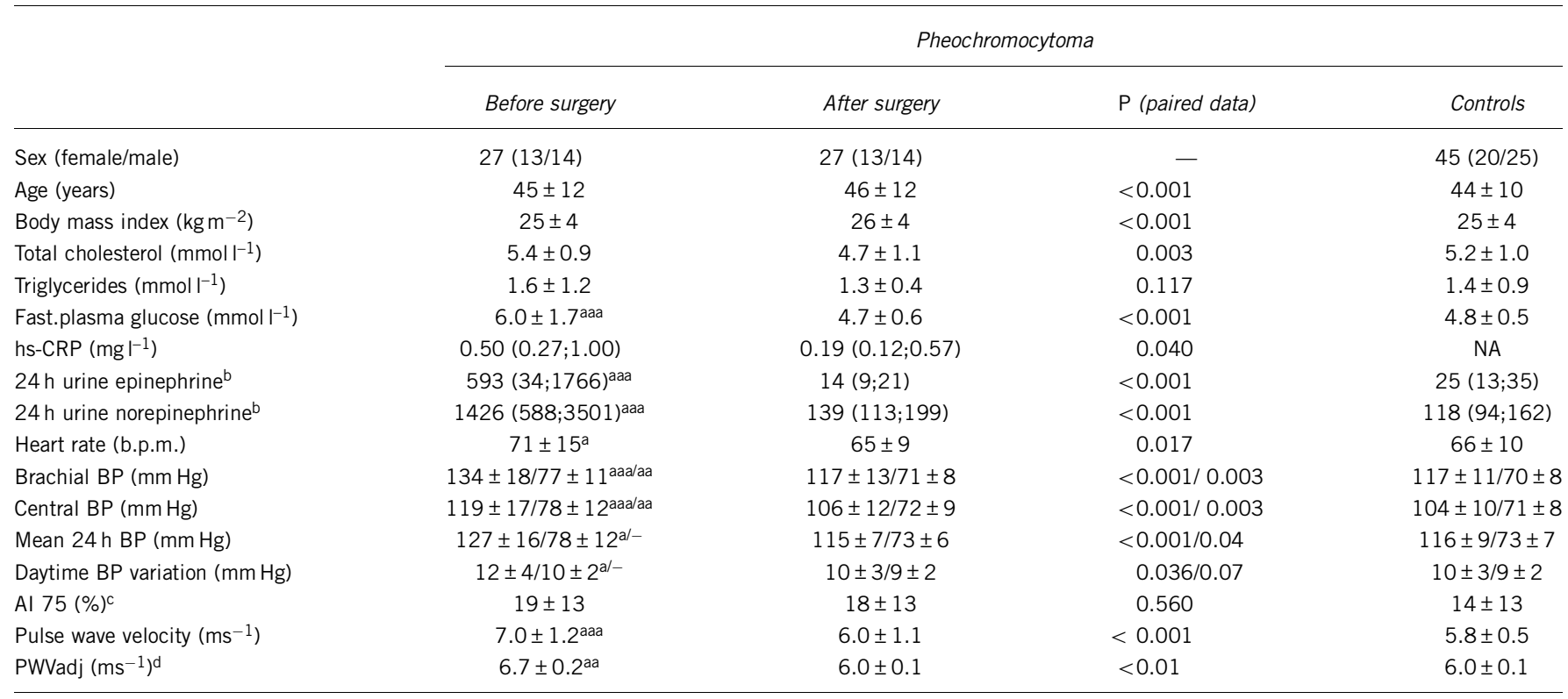

Abbreviations: Al, augmentation index; BP, blood pressure; hs-CRP, high-sensitive C-reactive protein.

Values are means \pm s.d. or medians (interquartile range).

a $P<0.05$, aa $P<0.01$, aaa $P<0.001$ baseline PHEO vs. $C$.

$b_{n m o l ~}{ }^{-1}$ creatinine.

${ }^{C}$ Augmentation index for heart rate 75 beats per min.

${ }^{\mathrm{d} A d j u s t e d ~ f o r ~ a g e, ~ h e a r t ~ r a t e, ~ b r a c h i a l ~ m e a n ~ b l o o d ~ p r e s s u r e ~ a n d ~ f a s t i n g ~ p l a s m a ~ g l u c o s e . ~}$

and protein cross-links in the arterial wall. ${ }^{36}$ Nevertheless, PWV in PHEO remained higher compared with $\mathrm{C}$ even after the adjustment for glucose level.

Higher BP variability may also be involved in the observed increase in arterial stiffness in patients with PHEO. In our earlier study, we found that excess of catecholamines in patients with PHEO is associated with higher daytime BP variability when compared with essential hypertensives, regardless of antihypertensive therapy. ${ }^{37}$ The relationship between $24 \mathrm{~h}$ systolic BP variability and PWV was found in hypertensive patients. ${ }^{38}$ We have observed mild significant relationship between PWV and daytime systolic BP variability. Thus, daytime BP variability may be also involved in arterial stiffening in PHEO.

Finally, chronic inflammatory process may also contribute to arterial stiffness. ${ }^{15}$ Elevated markers of inflammation have been shown to correlate positively with arterial stiffness in essential hypertension and chronic inflammatory diseases. ${ }^{39,40}$ In our recent study, 


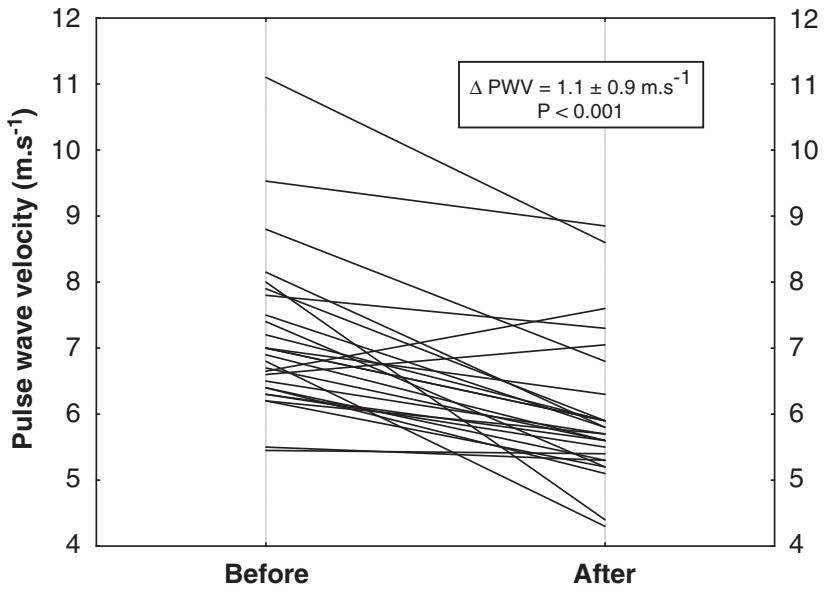

Figure 2 The change in PWV after tumor removal in patients with pheochromocytoma.

we have shown that chronic catecholamine excess in patients with PHEO is accompanied by an increase in inflammatory markers, which was reversed by the tumor removal. ${ }^{41}$ In this study, we have found significant association between hs-CRP and PWV.

Our study is limited by relatively small sample size of patients because of rare occurrence of PHEO. To clarify the differences between patients with predominantly norepinephrine- and epinephrine-secreting PHEO, larger studies are needed. Another confounding factor could be the treatment with $\alpha 1$-adrenoceptor blockers and/or verapamil in some patients because of high suspicion to PHEO based on earlier results in these patients. This short-term pretreatment with $\alpha 1$ adrenoceptor blockers and/or verapamil was initiated to decrease the risk of potential cardiovascular complications. On the other hand, catecholamines, as well as other hormonal levels, are minimally affected by this therapy. ${ }^{42}$ Vasodilator effect of these drugs may explain why no significant between-group differences in the AI were found. The AI is a composite measure that depends on PWV, the site of reflection and the amplitude of reflected wave. The normal AI in the setting of elevated PWV may, therefore, indicate reduced wave reflection, possibly because of reduced impedance mismatch at the reflection site because of peripheral vasodilatation. Vasoactive drugs have direct and more impact on $\mathrm{AI}$ than on PWV, as the aorta contains much less smooth muscle cells. Therefore, vasoactive drugs may change the AI independently from PWV. ${ }^{43}$ Furthermore, AI assessment is more operator dependent and less robust than PWV measurement. Although linear relationship between PWV and AI was repeatedly found, ${ }^{44}$ some investigators reported a weaker correlation and considered PWV to be a more precise marker of central vessels stiffness. ${ }^{45}$ Nevertheless, the tendency to higher AI levels in PHEO patients compared with controls was evident.

In conclusion, our study shows that patients with PHEO have higher carotid-femoral PWV as index of aortic stiffness, which is completely reversed by the successful tumor removal; not only age, mean blood pressure, but also hs-CRP and norepinephrine levels are independent predictors of PWV in patients with PHEO. Higher aortic stiffness may contribute to an increased cardiovascular risk in PHEO patients.

\section{ACKNOWLEDGEMENTS}

We highly appreciate the statistical help of Dr D Wichterle and technical assistance of Mrs L Landová. This study was supported by the Research Projects MSM-0021620807, MSM-0021620817 and MSM-0021620808 of The Ministry of Education, Czech Republic, Research Project MZOVFN2005 and IGA NT/11291-5 of the Ministry of Health, Czech Republic.

1 Porteri E, Rizzoni D, Mulvany MJ, De Ciuceis C, Sleiman I, Boari GE, Castellano M, Muiesan ML, Zani F, Rosei EA. Adrenergic mechanisms and remodeling of subcutaneous small resistance arteries in humans. J Hypertens 2003; 21: 2345-2352.

2 Mancia G, Grassi G, Giannattasio C, Seravalle G. Sympathetic activation in the pathogenesis of hypertension and progression of organ damage. Hypertension 1999; 34(4 Part 2): 724-728.

3 O'Callaghan CJ, Williams B. The regulation of human vascular smooth muscle extracellular matrix protein production by alpha- and beta-adrenoceptor stimulation. $J$ Hypertens 2002; 20: 287-294.

4 Ward MR, Pasterkamp G, Yeung AC, Borst C. Arterial remodeling. Mechanisms and clinical implications. Circulation 2000; 102: 1186-1191.

5 Boutouyrie P, Tropeano Al, Asmar R, Gautier I, Benetos A, Lacolley P, Laurent S. Aortic stiffness is an independent predictor of primary coronary events in hypertensive patients: a longitudinal study. Hypertension 2002; 39: 10-15.

6 Blacher J, Asmar R, Djane S, London GM, Safar ME. Aortic pulse wave velocity as a marker of cardiovascular risk in hypertensive patients. Hypertension 1999; 33: 1111-1117.

7 Amar J, Ruidavets JB, Chamontin B, Drouet L, Ferrieres J. Arterial stiffness and cardiovascular risk factors in a population-based study. J Hypertens 2001; 19: 381-387.

8 Laurent S, Boutouyrie P, Asmar R, Gautier I, Laloux B, Guize L, Ducimetiere P, Benetos A. Aortic stiffness is an independent predictor of all-cause and cardiovascular mortality in hypertensive patients. Hypertension 2001; 37: 1236-1241.

9 Laurent S, Katsahian S, Fassot C, Tropeano AI, Gautier I, Laloux B, Boutouyrie P. Aortic stiffness is an independent predictor of fatal stroke in essential hypertension. Stroke 2003; 34: 1203-1206.

10 Willum-Hansen T, Staessen JA, Torp-Pedersen C, Rasmussen S, Thijs L, Ibsen H, Jeppesen J. Prognostic value of aortic pulse wave velocity as index of arterial stiffness in the general population. Circulation 2006; 113: 664-670.

11 Shokawa T, Imazu M, Yamamoto H, Toyofuku M, Tasaki N, Okimoto T, Yamane K, Kohno N. Pulse wave velocity predicts cardiovascular mortality: findings from the Hawaii-Los Angeles-Hiroshima study. Circ J 2005; 69: 259-264.

12 O'Rourke M. Mechanical principles in arterial disease. Hypertension 1995; 26: 2-9.

13 Schram MT, Henry RM, van Dijk RA, Kostense PJ, Dekker JM, Nijpels G, Heine RJ, Bouter LM, Westerhof N, Stehouwer CD. Increased central artery stiffness in impaired glucose metabolism and type 2 diabetes: the Hoorn Study. Hypertension 2004; 43: $176-181$.

14 Blacher J, Safar ME, Pannier B, Guerin AP, Marchais SJ, London GM. Prognostic significance of arterial stiffness measurements in end-stage renal disease patients. Curr Opin Nephrol Hypertens 2002; 11: 629-634.

15 Virdis A, Ghiadoni L, Plantinga Y, Taddei S, Salvetti A. C-reactive protein and hypertension: is there a causal relationship? Curr Pharm Des 2007; 13: 1693-1698.

16 Lenders JW, Eisenhofer G, Mannelli M, Pacak K. Phaeochromocytoma. Lancet 2005; 366: 665-675.

17 Zelinka T, Eisenhofer G, Pacak K. Pheochromocytoma as a catecholamine producing tumor: implications for clinical practice. Stress (Amsterdam, Netherlands) 2007; 10: 195-203.

18 Widimský Jr J. Recent advances in the diagnosis and treatment of pheochromocytoma. Kidney Blood Press Res 2006; 29: 321-326.

19 Bernini G, Franzoni F, Galetta F, Moretti A, Taurino C, Bardini M, Santoro G, Ghiadoni L, Bernini M, Salvetti A. Carotid vascular remodeling in patients with pheochromocytoma. J Clin Endocrinol Metab 2006; 91: 1754-1760.

20 Holaj R, Zelinka T, Wichterle D, Petrak O, Strauch B, Vrankova A, Majtan B, Spacil J, Malik J, Widimsky Jr J. Increased carotid intima-media thickness in patients with pheochromocytoma in comparison to essential hypertension. J Human Hypertens 2009; 23: 350-358.

21 Bernini G, Galetta F, Franzoni F, Bardini M, Taurino C, Moretti A, Bernini M, Berti P, Miccoli P, Salvetti A. Normalization of catecholamine production following resection of phaeochromocytoma positively influences carotid vascular remodelling. Eur J Endocrinol 2008; 159: 137-143.

22 Galetta F, Bernini G, Franzoni F, Tocchini L, Taurino C, Bardini M, Rossi M, Salvetti A, Santoro G. Preclinical cardiac involvement in phaeochromocytoma: a study with integrated backscatter. Clin Endocrinol 2008; 68: 756-761.

23 IDF Clinical Guidelines Task Force. Global Guideline for Type 2 Diabetes: recommendations for standard, comprehensive, and minimal care. Diabet Med 2006; 23: 579-593.

24 O'Rourke MF, Pauca A, Jiang XJ. Pulse wave analysis. Br J Clin Pharmacol 2001; 51: 507-522.

25 Filipovský J, Svobodová V, Pecen L. Reproducibility of radial pulse wave analysis in healthy subjects. J Hypertens 2000; 18: 1033-1040.

26 Faber JE, Yang N, Xin X. Expression of alpha-adrenoceptor subtypes by smooth muscle cells and adventitial fibroblasts in rat aorta and in cell culture. J Pharmacol Exp Ther 2001; 298: 441-452.

27 Head RJ. Hypernoradrenergic innervation and vascular smooth muscle hyperplastic change. Blood Vessels 1991; 28: 173-178. 
28 Johnson MD, Grignolo A, Kuhn CM, Schanberg SM. Hypertension and cardiovascular hypertrophy during chronic catecholamine infusion in rats. Life Sci 1983; 33: 169-180.

29 Jonsson JR, Head RJ, Frewin DB. Effect of alpha 1-adrenoceptor blockade on the development of hypertension in the spontaneously hypertensive rat. Eur J Pharmacol 1992; 211: 263-268.

30 Zhang H, Faber JE. Trophic effect of norepinephrine on arterial intima-media and adventitia is augmented by injury and mediated by different alphal-adrenoceptor subtypes. Circ Res 2001; 89: 815-822.

31 Dinenno FA, Jones PP, Seals DR, Tanaka H. Age-associated arterial wall thickening is related to elevations in sympathetic activity in healthy humans. Am J Physiol Heart Circ Physiol 2000; 278: H1205-H1210.

32 Grassi G. Role of the sympathetic nervous system in human hypertension. J Hypertens 1998; 16(12 Part 2): 1979-1987.

33 Grassi G, Seravalle G, Turri C, Mancia G. Sympathetic nerve traffic responses to surgical removal of pheochromocytoma. Hypertension 1999; 34: 461-465.

34 Turnbull DM, Johnston DG, Alberti KG, Hall R. Hormonal and metabolic studies in a patient with a pheochromocytoma. J Clin Endocrinol Metab 1980; 51: 930-933.

35 Henry RM, Kostense PJ, Spijkerman AM, Dekker JM, Nijpels G, Heine RJ, Kamp O, Westerhof N, Bouter LM, Stehouwer CD. Arterial stiffness increases with deteriorating glucose tolerance status: the Hoorn Study. Circulation 2003; 107: 2089-2095.

36 Singh R, Barden A, Mori T, Beilin L. Advanced glycation end-products: a review. Diabetologia 2001; 44: 129-146.
37 Zelinka T, Strauch B, Petrak O, Holaj R, Vrankova A, Weisserova H, Pacak K, Widimsky $\mathrm{Jr} \mathrm{J}$. Increased blood pressure variability in pheochromocytoma compared to essential hypertension patients. J Hypertens 2005; 23: 2033-2039.

38 Ichihara A, Kaneshiro Y, Takemitsu T, Sakoda M, Hayashi M. Ambulatory blood pressure variability and brachial-ankle pulse wave velocity in untreated hypertensive patients. J Human Hypertens 2006; 20: 529-536.

39 Mahmud A, Feely J. Arterial stiffness is related to systemic inflammation in essential hypertension. Hypertension 2005; 46: 1118-1122.

40 Roman MJ, Devereux RB, Schwartz JE, Lockshin MD, Paget SA, Davis A, Crow MK, Sammaritano L, Levine DM, Shankar BA, Moeller E, Salmon JE. Arterial stiffness in chronic inflammatory diseases. Hypertension 2005; 46: 194-199.

41 Zelinka T, Petrák O, Štrauch B, Holaj R, Kvasnička J, Mazoch J, Pacák K, Widimský Jr J. Elevated inflammation markers in pheochromocytoma compared to other forms of hypertension. Neuroimmunomodulation 2007; 14: 57-64.

42 Pacak K, Lenders JWM, Eisenhofer G. Pheochromocytoma: Diagnosis, Localization, and Treatment. Blackwell: Oxford, 2007. vi, $172 \mathrm{pp}$.

43 Kelly RP, Millasseau SC, Ritter JM, Chowienczyk PJ. Vasoactive drugs influence aortic augmentation index independently of pulse-wave velocity in healthy men. Hypertension 2001; 37: 1429-1433.

44 Yasmin, Brown MJ. Similarities and differences between augmentation index and pulse wave velocity in the assessment of arterial stiffness. Qjm 1999; 92: 595-600.

45 Schiffrin EL. Vascular stiffening and arterial compliance. Implications for systolic blood pressure. Am J Hypertens 2004; 17(12 Part 2): 39S-48S. 